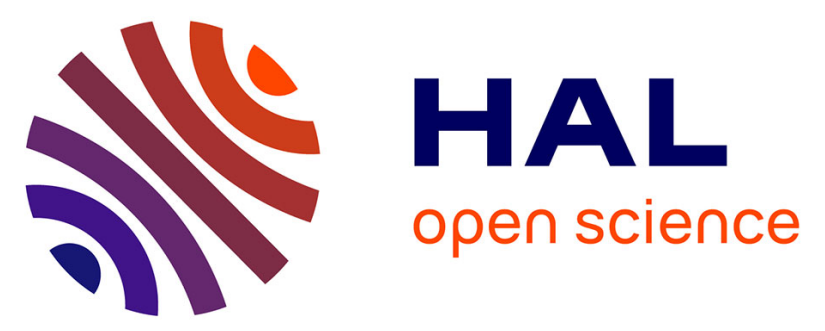

\title{
Prediction of displacement rates at an active landslide using joint inversion of multiple time series
}

Clara Lévy, Scarlett Gendrey, Séverine Bernardie, Marie-Aurélie Chanut, Aurélien Vallet, Laurent Dubois, Jean-Paul Duranthon

\section{- To cite this version:}

Clara Lévy, Scarlett Gendrey, Séverine Bernardie, Marie-Aurélie Chanut, Aurélien Vallet, et al.. Prediction of displacement rates at an active landslide using joint inversion of multiple time series. 4th World Landslide Forum, May 2017, Ljubljana, Slovenia. pp.WLFO-D-16-00074R3, 10.1007/978-3319-53487-9_9. hal-01495318

\section{HAL Id: hal-01495318 https://hal.science/hal-01495318}

Submitted on 24 Mar 2017

HAL is a multi-disciplinary open access archive for the deposit and dissemination of scientific research documents, whether they are published or not. The documents may come from teaching and research institutions in France or abroad, or from public or private research centers.
L'archive ouverte pluridisciplinaire HAL, est destinée au dépôt et à la diffusion de documents scientifiques de niveau recherche, publiés ou non, émanant des établissements d'enseignement et de recherche français ou étrangers, des laboratoires publics ou privés. 


\title{
Prediction of displacement rates at an active landslide using joint inversion of multiple time series
}

Clara Lévy, Scarlett Gendrey, Séverine Bernardie, Marie-Aurélie Chanut, Aurélien Vallet, Laurent Dubois and Jean-Paul Duranthon

\begin{abstract}
This work focuses on the development of FLAME (Forecasting Landslides induced by Acceleration Meteorological Events) that analyze of the relationship between displacements and precipitations using a statistical approach in order to predict the surface displacement at active landslide. FLAME is an Impulse Response model (IR) that simulates the changes in landslide velocity by computing a transfer function between the input signal (e.g. rainfall or recharge) and the output signal (e.g. displacement). This model has been applied to forecast the displacement rates at Séchilienne (French Alps). The FLAME model is enhanced by achieving the calibration using joint inversion of multiple time series data. We consider that the displacements at two different sensors are explained by the same long-term response of the system to ground water level variations. The parameters describing the long-term response of the system are therefore identical for all sensors. The joint inversion process allows decreasing the ratio between the number of parameters to be inverted and the volume of data and is thus more statically steady. The results indicate that the models are able to reproduce the displacement pattern in general to moderate kinetic regime but not extreme kinetic regime. Our results do not give clear evidence of an improvement of the models performance with joint inversion of multiple time series of data. The reasons which could explain these inconclusive results are discussed in the paper.
\end{abstract}

Keywords

Landslide, displacement pattern, prediction, monitoring, joint inversion

\section{Introduction}

Recently, statistical models using impulse responses functions had been used to successfully predict landslides velocities (Belle et al. 2014; Abellan et al. 2013). Not only these models facilitate displacement prediction based on a limited data set (Belle et al. 2014), but they also proved appropriate to take into account possible temporal variations of the landslide properties (Bernardie et al. 2014; Abellan et al. 2015). Such models predict a behavior of the landslide similar to the period used to calibrate the model. Consequently, when the landslide deformation rate increases and thereby causes a rapid change of the landslide rheological and hydrological properties, the discrepancy between predicted and actual measurements increases. Bernardie et al. (2014) showed that this indication of a change in the landslide behavior could be used to predict fluidization events at the Super-Sauze landslide, several days in advance. At Super-sauze, a threshold criterion of the error of prediction was estimated by performing back analysis on several fluidization events.
The definition of thresholds values for real-time early warning systems becomes tricky for study-sites such as Séchilienne that never experienced a major crisis. One way to identify periods when the observed velocities significantly differ from the predicted velocities would be to assess the quality of the velocity predictions and to estimate an error envelope of these predictions. Thus, prior to apply such methods, we must ensure the quality of model predictions. Unfortunately, the studies aforementioned also showed that this latter type of statistical models usually presents some defaults. In particular, the inversion process can be rather instable when choosing to calibrate a model accounting for a complex hydrogeological response (i.e., with numerous parameters to be determined by inversion) using short time series of data.

Therefore, the improvement of the model predictions is an important step to help defining critical values of velocities. This study discusses the enhancement of the method by achieving the calibration of the model using joint inversion of 
multiple time series of data. The method is applied at the Séchilienne landslide where the geometry of the instrumentation meets the requirement of the method. In detail, it means that the displacement rate sensors are located on top of the same hydrogeological unit, thus allowing considering partially identical Impulse Response models for all the inverted time series. By doing so, the ratio between the number of parameters to be inverted and the volume of data decreases, thus $a$ priori improving the robustness of the method. The first part of this paper details the current understanding of the hydrogeological behavior of the Séchilienne landslide. The second part of this paper presents the statistical model used in this study to predict surface velocities at the Séchilienne landslide. Finally we discuss the benefits of using joint inversion of multiple time series of data for the prediction of the displacement rates at active landslides using Impulse Response models.

\section{Description of the Séchilienne landslide}

\section{Location, geometry}

The Séchilienne landslide is located in the South-east of Grenoble in the French Alps (Fig1).

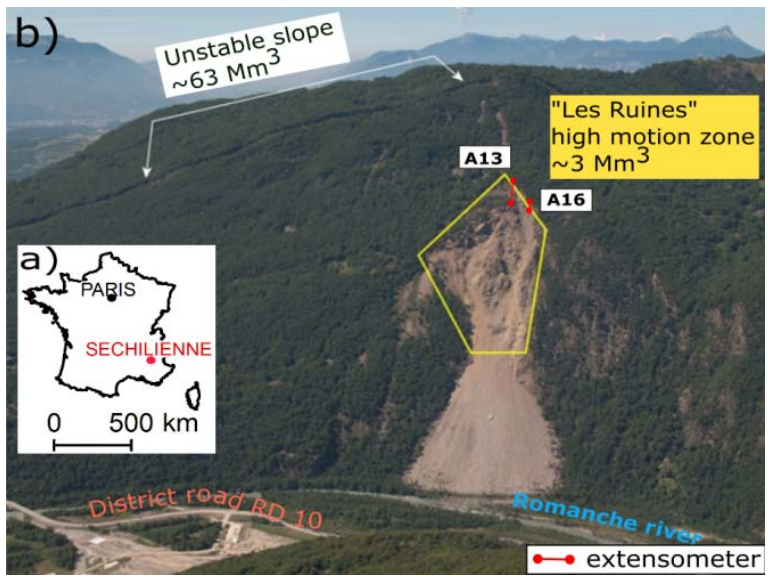

Fig. 1 a) Localization of the Séchilienne landslide on the French Alps map. b) Photograph of the Séchilienne slope in July 2014, with the limits of "Les Ruines" high motion zone in yellow, and the upper limit of the whole unstable mass in white. The positions of extensometers $\mathrm{A}_{13}$ and A16 are indicated in red.

The whole unstable mass is estimated between 48 and 63 million $\mathrm{m}^{3}$ (Le Roux et al. 2011). Most of the unstable mass moves slowly with velocities ranging from 2 to $15 \mathrm{~cm} /$ year on average, except for a very active moving zone with velocities ranging from 150 to 300 $\mathrm{cm} /$ year on average (Vallet et al. 2015b). Rock falls occurs on a regular basis within this active zone which volume is estimated at 3 million $\mathrm{m}^{3}$ (Le Roux et al. 2011). A particularity of the Séchilienne landslide is the absence of a well-define basal sliding surface.

\section{Kinetics and hydrogeology}

The influence of recharge on the kinematics of the Séchilienne landslide has been evidenced by numerous studies: Rochet et al. 1994; Alfonsi 1997; Durville et al. 2009; Chanut et al. 2013. Recently, Vallet et al. (2015b) showed that the massif at Séchilienne hosts a relatively shallow perched aquifer in the unstable zone and a deep aquifer in the intact massif. The existence of the shallow perched aquifer is related to the permeability contrast between the unstable mass at shallow depth and at deeper depth. Authors described the perched aquifer, with an extent and connectivity dependent on the seasonal recharge. For both aquifers, conductive fractures play a major role in the drainage (Vallet et al. 2015b).

Cappa et al. (2014), and more recently Vallet et al. (2015b) investigated the link between the Séchilienne landslide kinematics and the local hydrogeology. Both showed that low frequency displacement of the landslide might be linked with variations of the deep aquifer level, and whereas the high frequency displacements of the landslide might by linked with variations of the perched aquifer level in the landslide.

The existence of this deep aquifer has never been evidence by drilling experiments (since its depth is lower than $-150 \mathrm{~m}$ ). Its depth and geometry are not well known and this deep aquifer might correspond to water circulation inside a fracture network.

\section{Monitoring network}

The Séchilienne landslide is monitored since 1985 by the French public national body Cerema Centre Est (Duranthon et al. 2003; Dubois et al. 2014). Precipitations are recorded at the Mont-Sec weather station, located a few hundred meters above the disturbed zone. This station is equipped with both a rain and a snow gauge, thereby allowing the estimation of snow cover and snow melt in water equivalent.

The landslide displacements are monitored using a variety of techniques (extensometers, radar, infra-red, inclinometers and GPS). In this study, we analyze displacements at extensometers $\mathrm{A}_{13}$ an $\mathrm{A}_{1} 6$, both located within the active moving zone (see Figure 1b). The measurements show the same general trends (see Fig. 5a). The extensometers are characterized by measurement errors of $\pm 0.5 \mathrm{~mm}$. 


\section{Description of the forecasting model FLAME}

We use the statistical model FLAME (Bernardie et al. 2014) to predict surface velocities at the Séchilienne landslide.

FLAME is an Impulse Response model, which principle is to reproduce an output signal $S$ (e.g. displacement) using the convolution product of an input signal $E$ (e.g. rainfall or recharge) by a transfer function $\Gamma$ as described in Eq.1 and Fig.2:

$S(n . d t)=\Gamma * E(t)=\sum_{i=1}^{k} \Gamma(i \cdot d t) \cdot E((n-i+1) \cdot d t)[1]$

where $n$ is the discretized interval time, and $k$ is the order (length) of the impulse response.

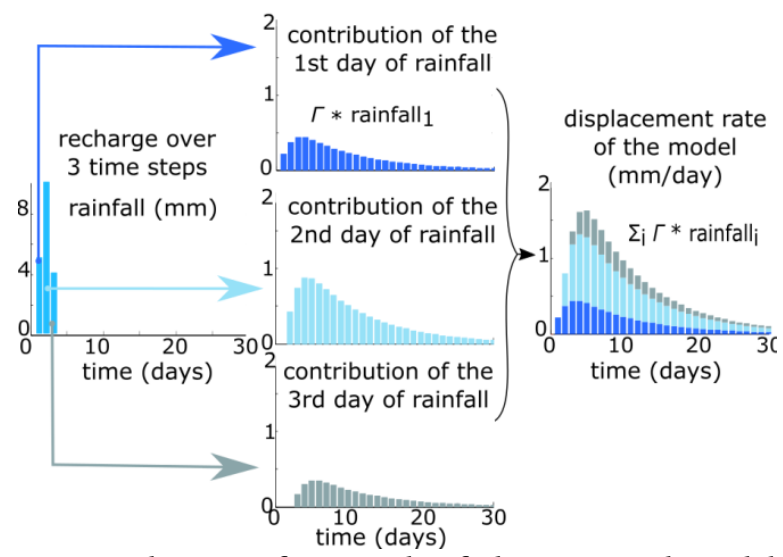

Fig. 2 Schematic framework of the statistical model FLAME

During the calibration phase, an optimization of the parameters describing the transfer function $\Gamma$ is performed in order to minimize the Root Mean Square Error (RMSE) of the difference between the estimated displacement rates and the observed displacement rates. The calibration model is then used to forecast the displacement rates coming just after the calibration period (Fig.3).

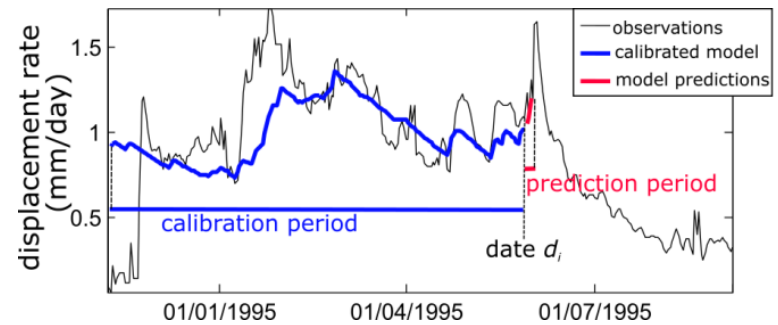

Fig. 3 Calibration of the model using observed displacement rate befor the date $d_{i}$; and prediction of the displacement rate with the calibrated model for dates $d_{i+1}$ and $d_{i+2}$.
The calibration of the models is repeated daily, using a moving calibration period of 200-days. This "sliding calibration window" enables to account for temporal changes in the rheological and hydrological response of the slope. The length of the calibration period was set at 200-days so that: $(1)$ it is long enough to invert a transfer function $\Gamma$ that matches seasonal variations of the landslide behavior and, (2) this calibration period is short enough to consider that the medium is a time-invariant system and can be characterized by a unique transfer function $\Gamma$. The transfer functions $\Gamma_{i}$ determined thank to the inversion process at date $d_{i}$ are used to predict the displacement rate at dates $d_{i+1}$ to $d_{i+20}$.

The transfer functions $\Gamma_{i}$ of the FLAME model (Eq.2) are the convolution of a Gaussian function (e.g. representing the recharge of the water reservoir) by an exponential function (e.g. representing the discharge of the water reservoir):

$$
\Gamma(t)=\exp \left(-\ln (2)\left(\frac{t-T}{D}\right)^{2} * \exp \left(-t \frac{\ln (2)}{L}\right)\right)
$$

For each $\Gamma_{i}$, the three degrees of freedom to optimize are:

$T \geq 0$ : the position of Gaussian (e.g. time delay between the recharge and the rainfall; in day);

$D>0$ : the width at middle height of the Gaussian (e.g. time duration of the phenomenon; in day);

- $\quad L$ : the half time duration of the drainage of the water reservoir (in day)

The transfer functions are normalized, considering a coefficient defined by the conservation law between inputs and outputs (Eq.3):

$$
c=\frac{\sum S(t)}{\sum E(t)}
$$

\section{Joint inversion}

The displacement rates at the Séchilienne landslide are influenced by the deep aquifer as well as by the perched aquifer. Thus, the transfer function of the model should account for both aquifers and Eq.1 would become, for each sensor:

$S=\beta\left[\gamma_{d a} \cdot\left(\Gamma_{d a} * E(t)+c s t_{d a}\right)+\gamma_{p a} \cdot\left(\Gamma_{p a} * E(t)+c s t_{p a}\right)\right][4]$

where $\beta$ is a normalization constant, and $\gamma$ and $\Gamma$, respectively, are the contribution coefficient and the transfer function of the input $E$ (e.g., the water input), and cst, a constant corresponding to constant contribution. Indices $d a$ and $p a$ stand for deep aquifer and perched aquifer, respectively. 
This transfer function has 6 degrees of freedom, which have to be optimized during the calibration phase. On a first attempt (case 1), the transfer function $\Gamma$ is simplified so as to account only for one aquifer:

$$
S=\beta\left[\gamma_{d a} \cdot\left(\Gamma_{d a} * E(t)+c s t_{d a}\right)\right]
$$

where only 3 degrees of freedom are to be optimized during the calibration phase.

On a second attempt (case 2), the complete transfer function $\Gamma$ is considered:

$S=\beta\left[\gamma_{d a} \cdot\left(\Gamma_{d a} * E(t)+c s t_{d a}\right)+\gamma_{p a} \cdot\left(\Gamma_{p a} * E(t)+c s t_{p a}\right)\right]$

where 6 degrees of freedom are to be optimized during the calibration phase.

The calibration of these transfer functions can be performed independently for the time series of $\mathrm{A}_{13}$ and $\mathrm{A} 16$.

In this study, we also propose to perform the joint inversion of the $\mathrm{A}_{13}$ and A 16 time series. The principle of the joint inversion is to assume a similar influence of the deep aquifer on the displacement rates at $A_{13}$ and A16 (both sensors are located on top of the same hydrogeological unit), whereas such conclusion cannot be derived for the influence of the perched aquifer, described as temporary, with an extent and connectivity dependent on the seasonal recharge. Thus, during the joint inversion, the parameters corresponding to the influence of the deep aquifer will be considered identical for all sensors, whereas the parameters corresponding to the influence of the perched aquifer will be considered different. By doing so, the ratio between the number of parameters to be inverted and the volume of data decreases. The constraint on the inversion process is enhanced.

The joint inversion is performed for the period during which all sensors are operative, from the 24/02/1994, until the 30/06/2013.

\section{Water inputs}

The input signal $E$ (see Eq. 4) representing water inputs will be considered as the recharge for the deep aquifer (i.e., the amount of water that is available for infiltration after evapotranspiration), and as the precipitations for the perched aquifer (e.g. the sum of rain and snow melt). The recharge is estimated using the model of Vallet et al. (2015a) (see Fig. 4).

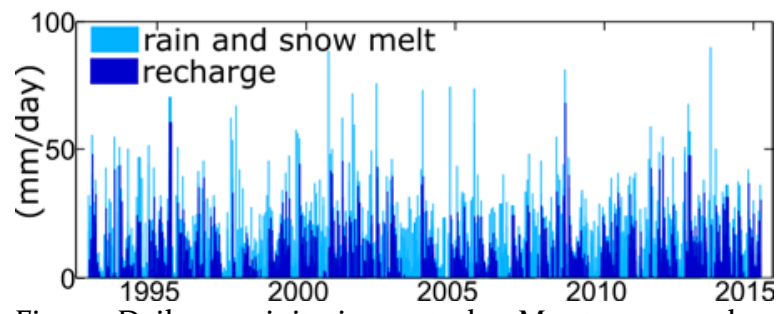

Fig. 4 Daily precipitations at the Mont-sec weather station, and the estimated recharge using the model of Vallet et al. (2015a) at the Séchilienne landslide.

\section{Parameter space}

During the inversion process, a large parameter space is investigated in order to optimize the value of the transfer function parameters. This parameter space is chosen so as to cover a large range of realistic values for the Séchilienne landslide (see Tab. 1).

\begin{tabular}{|c|c|c|} 
Parameter & $\begin{array}{c}\text { Lowest possible } \\
\text { value (days) }\end{array}$ & $\begin{array}{c}\text { Highest possible } \\
\text { value (days) }\end{array}$ \\
\hline$T_{d a}$ & 0 & 80 \\
$T_{p a}$ & 0 & 90 \\
\hline$L_{d a}$ & 1 & 80 \\
$L_{p a}$ & 1 & 300 \\
\hline$D_{d a}$ & 1 & 80 \\
$D_{p a}$ & 1 & 90 \\
\hline
\end{tabular}

\section{Assessment of the quality of the results}

The quality of the models will be assessed by analyzing the modelling errors. This error can be characterized by the RMSE of the difference between the observed displacement rate between date $d_{i+1}$ and date $d_{i+j}$, and the predicted displacement rate at the same dates; the lower the RMSE, the more accurate the model will be. Furthermore, we assessed the quality of the models computing the coefficient of determination $\left(\mathrm{R}^{2}\right)$ between the observed and the predicted velocities. The closer to one the $\mathrm{R}^{2}$ is, the more accurate the model will be. Finally, a visual inspection of the time-series shape was also carried out in order to investigate whether or not the predictions reproduced the characteristic behavior of the landslide, such as long term trends and seasonal variations.

\section{Simulation of displacement rates at the Séchilienne} Landslide

\section{Models using one transfer function $\Gamma_{d a}$}

Fig. 5 presents the results of models using one transfer function (see Eq. 5). Fig. 5a to 5c presents the results of independent inversions for sensors $A_{13}$ and $A_{1} 6$, when Fig. $5 \mathrm{~d}$ to $5 \mathrm{f}$ presents the results of joint inversion for sensors $A_{13}$ and A16. For both inversions, the predicted 
displacement rates at date $\mathrm{d}_{\mathrm{i}+1}$ reproduce the seasonal variations and the long term trend of the data (see Fig. $5 \mathrm{a}$ and $5 \mathrm{~d}$ ). Models have similar performance with: (1) a coefficient of determination $\mathrm{R}^{2}$ between the observed and the predicted velocities of 0.74 and 0.80 for sensors $\mathrm{A}_{16}$ and $\mathrm{A}_{13}$, respectively (see Fig. 5b and 5e), (2) a distribution of the model errors centered in zero (e.g., the difference between the observed displacement rate at date $d_{i+1}$ and the predicted displacement rates at the same date; see Fig. $5 \mathrm{c}$ and $5 \mathrm{f}$ ).

Despite an inversion process that is more contrained during joint inversion, the quality of the displacement predictions is similar. For all the models of Fig. 5, the average RSME of the predictions is about $0.91 \mathrm{~mm} /$ day after one day of prediction, and evolves to $0.96 \mathrm{~mm} /$ day after 20 days of prediction. The maximum error of prediction after 20 days evolves from 17.5 velocities ( $\mathrm{mm} /$ day)
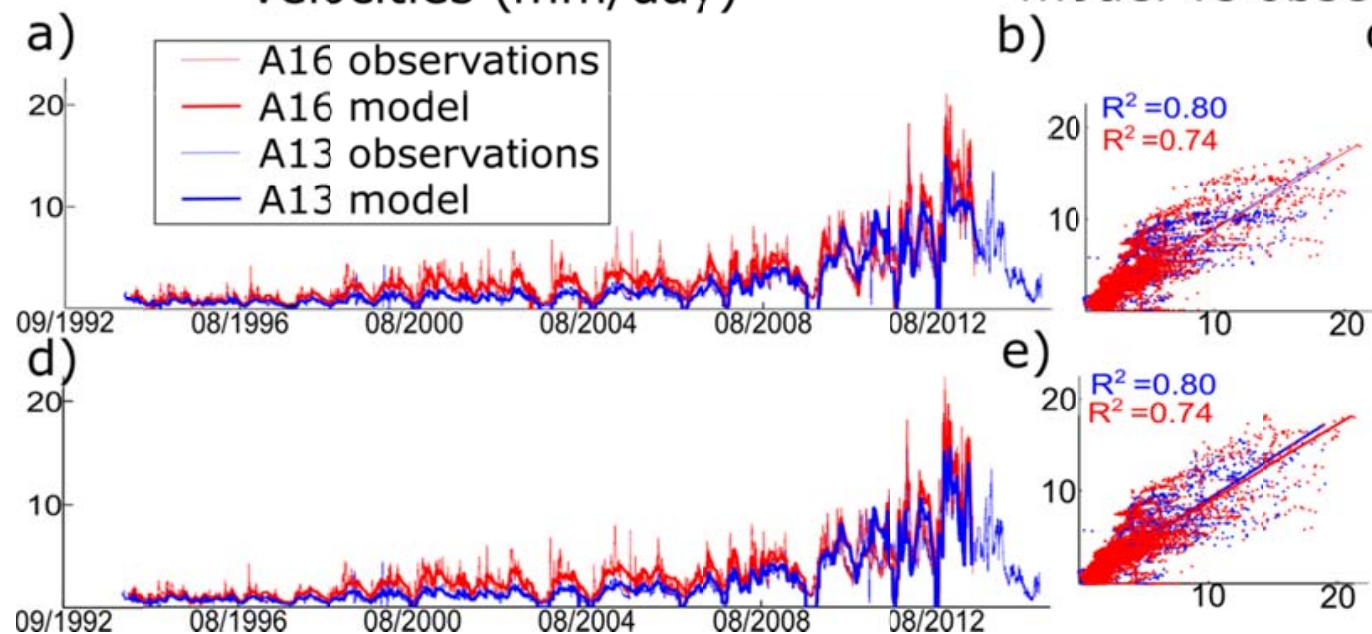

$\mathrm{mm}$ /day for models using independent to $16.3 \mathrm{~mm} /$ day for models using joint inversion. Aside from this difference, the quality of the long-term predictions of displacements is identical whatever the method of inversion.

The expected improvement of the model performance with joint inversion is not observed. One hypothesis to explain such results is that models using one transfer function cannot reproduce displacements due to the short-term response of the landslide to precipitations. Thus, the error of the models always remains higher than this short-term response. Hereafter, we propose to test models using two transfer functions, eventhough such models are more difficult to constraint due to their numerous degree of freedom.

Fig. 5 Models using one transfer function (see Eq. 5): a) Observed displacement rates at extensometers A13 and A16 compared to the predicted displacement rates using independent inversions for sensors $A_{13}$ and A16. b) The predicted displacement rates at $A_{13}$ and A16 of Fig. 5a as a function of the observed displacement rates. Model performance assessment through linear regression and the value of $\mathrm{R}^{2}$. c) distribution of the model errors (observations vs. model outcomes). d) to f) same as a) to c) for predicted displacement rates using joint inversions for sensors $A_{13}$ and $A_{1} 6$.

\section{Models using two transfer functions $\Gamma_{d a}$ and $\Gamma_{p a}$}

Fig. 6 presents the results of models using two transfer functions (see Eq. 6). Fig. 6a to $6 \mathrm{c}$ presents the results of independent inversions for sensors $\mathrm{A}_{13}$ and A16, when Fig. $6 \mathrm{~d}$ to $6 \mathrm{f}$ presents the results of joint inversion for sensors $A_{13}$ and $A_{1} 6$. For both inversions, the predicted displacement rates at date $d_{i+1}$ reproduce the seasonal variations and the long term trend of the data (see Fig. 6a and 6d and Fig. 6g and 6h). Models have similar performance with: (1) a coefficient of determination $\mathrm{R}^{2}$ between the observed and the predicted velocities of 0.87 and 0.90 for sensors A16 and A13, respectively (see Fig. $6 \mathrm{~b}$ and 6e), (2) a distribution of the model errors centered in zero (e.g., the difference between the observed displacement rate at date $d_{i+1}$ and the predicted displacement rates at the same date; see Fig. $6 c$ and 6f).

Despite an inversion process that is more contrained during joint inversion, the quality of the displacement predictions is similar. For all the models of Fig. 6, the average RMSE of the predictions is about $0.6 \mathrm{~mm} /$ day after one day of prediction, and evolves to $0.7 \mathrm{~mm} /$ day after 20 days of prediction. The maximum error of prediction after 20 days evolves from 14.8 $\mathrm{mm}$ /day for models using independent inversions for sensors $A_{13}$ and $A_{16}$, to $13.4 \mathrm{~mm}$ /day for models using joint inversion. Aside from this difference, the quality of the long-term predictions of displacements is 
identical whatever the method of inversion. The expected improvement of the model performance with joint inversion is not observed.

The quality of the results is clearly improved when using models with two transfer functions rather than models with one transfer function. The average RMSE of predictions gets closer to the measurement error of the sensors $( \pm 0.5 \mathrm{~mm} /$ day). This improvement does not allow asserting that the optimized parameters (T,L,D, see Eq. 2) are sufficiently constrained during the inversion and are representative of the averaged behavior of the landslide.

The evolution of the optimized parameters $T_{d a}, L_{d a}$ and $D_{d a}$ with time is studied for two distinct period $\mathrm{P}_{1}$ and $\mathrm{P}_{2}$ (see Fig. 6d, 6g and 6h) for the model using two transfer functions and joint inversion. Period P1 goes from the 06/05/2002 to the 14/08/2003; period $\mathrm{P}_{2}$ goes from the 22/12/2009 to the 19/11/2010. During period $\mathrm{P}_{1}$, the displacement rates have seasonal fluctuations with an increasing trend.

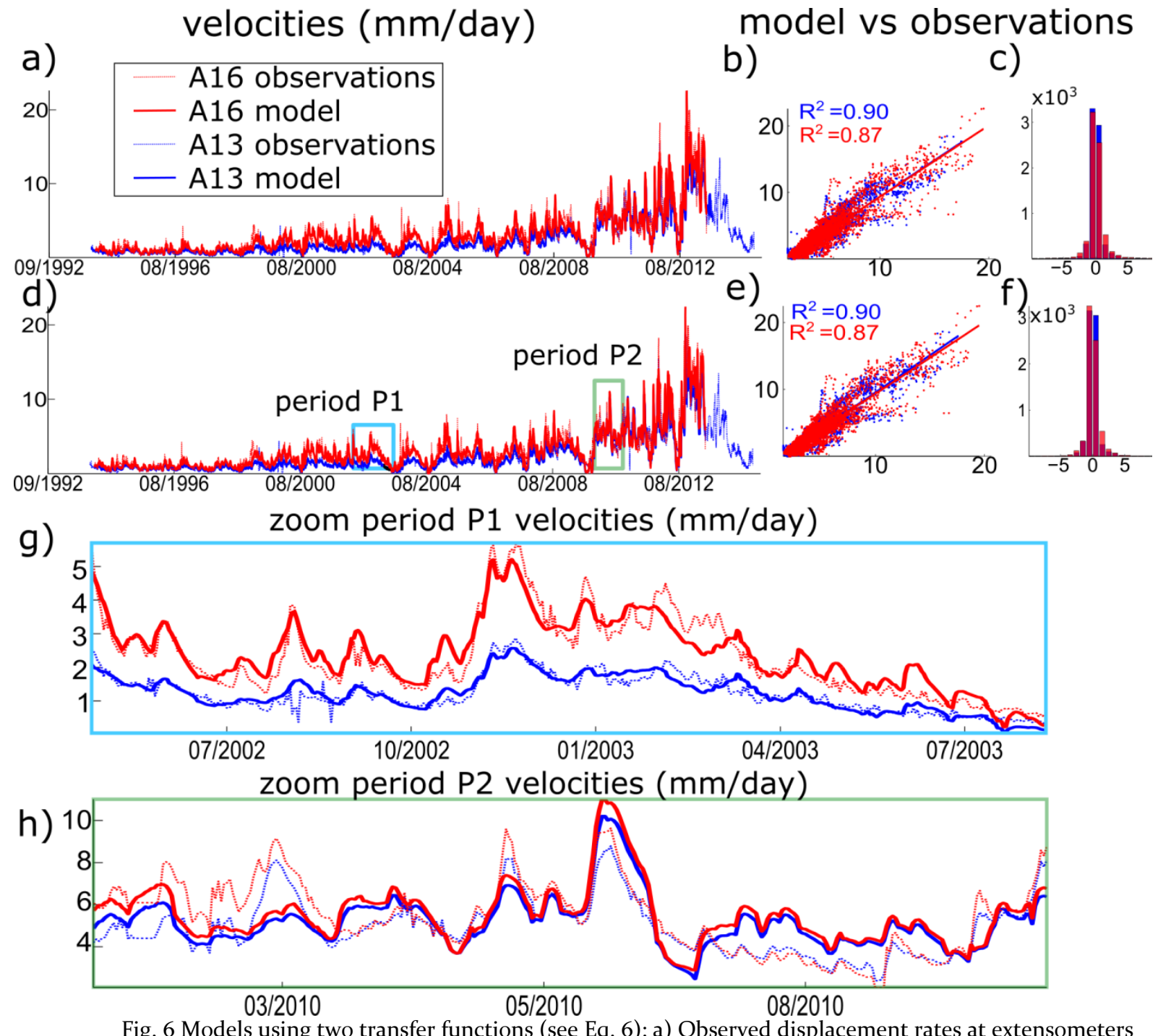

$A_{13}$ and $A_{1} 6$ compared to the predicted displacement rates using independent inversions for sensors $A_{13}$ and $A_{1} 6$. b) The predicted displacement rates at $\mathrm{A}_{13}$ and A16 of Fig. 6a as a function of the observed displacement rates. Model performance assessment through linear regression and the value of $\mathrm{R}^{2}$. c) distribution of the model errors (observations vs. model outcomes). d) to f) same as a) to c) for predicted displacement rates using joint inversions for sensors $A_{13}$ and A16. g) and h) zooms of Fig. 6d for the periods $P_{1}$ (from the 06/05/2002 to the 14/08/2003) and $\mathrm{P}_{2}$ (from the 22/12/2009 to the $19 / 11 / 2010$ ). 
During period $\mathrm{P}_{2}$, the displacement rates are more irregular and with more amplitude, together with a general increase of the average velocity. During both periods, the evolutions of the optimized parameters $T_{d a}$, $L_{d a}$ and $D_{d a}$ are gradual and never reach the limits of the defined parameter space (see Tab. 1). Fig. $7 \mathrm{a}, 7 \mathrm{~b}$ and $7 \mathrm{c}$ shows the distribution of the value of parameters $T_{d a}$, $L_{d a}$ and $D_{d a}$ for these two periods, as well as their average value. The corresponding shapes of the average transfer function $\Gamma_{d a}$ for periods $\mathrm{P}_{1}$ and $\mathrm{P}_{2}$ are presented on Fig. $7 \mathrm{~d}$. Both transfer functions $\Gamma_{d a}$ have realistic shapes, and represent distinct average behaviors that are consistent with the general increase of the average landslide velocity between periods $\mathrm{P}_{1}$ and $\mathrm{P}_{2}$ (the time response decreases between periods $\mathrm{P}_{1}$ and $\mathrm{P}_{2}$ ).

a)

b)

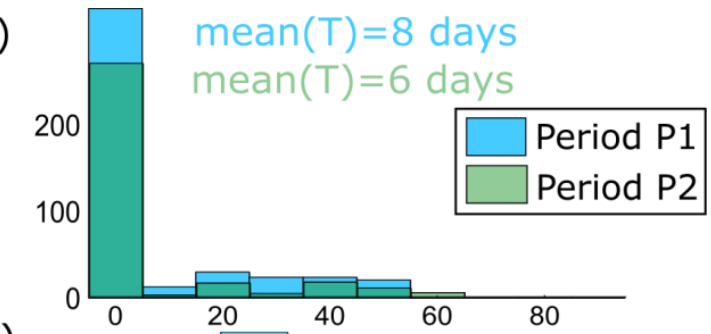

c)

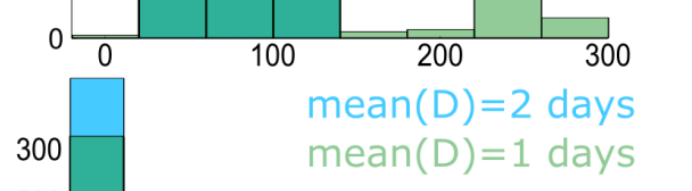

d)

200

100

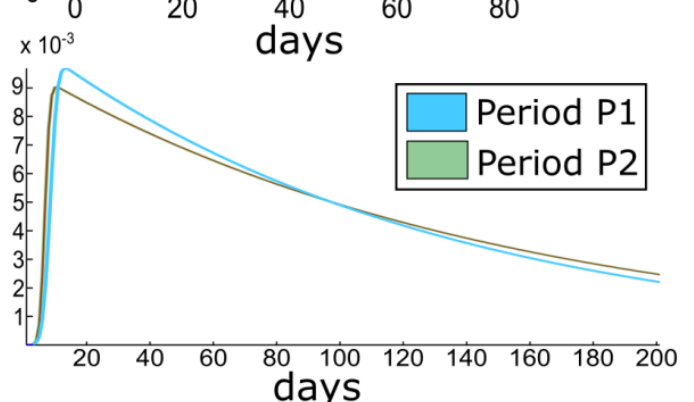

Fig. 7 a) Distribution and mean value of the $T$ parameter of the tranfer function $\Gamma_{d a}$ during periods P1 and $\mathrm{P}_{2}$ (see Fig. 6d, 6g and 6h). b) and c) same as a) for parameters $L$ and $D$ of the tranfer function $\Gamma_{d a}$ d) Shape of the average transfer function $\Gamma_{d a}$ for periods $\mathrm{P}_{1}$ and P2.

\section{Discussion}

This study discusses the use of statistical models using impulse responses functions to predict landslides velocities. The inversion processes of these statistical models can be poorly constrained when choosing to calibrate a model accounting for a complex hydrogeological response (i.e., with numerous parameters to be determined by inversion). The aim of this study was to test if an enhancement of the method could be achieved by calibrating the models using joint inversion of multiple time series of data.

The method was applied at the Séchilienne landslide where the geometry of the instrumentation meets the requirement of the method. E.g., the displacement rate sensors are located on top of the same hydrogeological unit, thus allowing considering partially identical Impulse Response models for all the inverted time series. By doing so, the ratio between the number of parameters to be inverted and the volume of data decreases, thus a priori increasing the constraint for the search of an optimized solution during inversion.

Our results do not give clear evidence of an improvement of the models performance with joint inversion of multiple time series of data. The reasons which could explain these inconclusive results are numerous. One unfavorable factor is certainly the fact that the data set could not allow a better characterization of the landslide short-term behavior. Data time step is only 24 hours, when the landslide short-term time response is of the order of a few hours (Vallet et al., 2015b). Thus, the convergence of the models to an adequate estimate of the short-term response of the landslide is difficult. Another unfavorable factor is that we assume that the medium is a time-invariant system for the duration of the calibration. If this approximation has a good chance of being correct for the seasonal variations of the landslide, it might not hold true for the short-term response of the landslide. There might be a conflict between the need of a sufficiently long calibration period to constrain the inversion of the long-term response of the landslide, and the necessary assumption to consider the response of the short-term of the landslide as invariant during this calibration period. 


\section{Acknowledgments}

The monitoring dataset at Séchilienne is part of the Cerema database (Website of Séchilienne rock slope instability: http://www.versantsechilienne.developpement-durable.gouv.fr/) and the OMIV Observatory (Observatoire Multidisciplinaire des Instabilités de Versants: http://omiv.unistra.fr)

\section{References (in the alphabetical order)}

Abellán, A., C. Michoud, M. Jaboyedoff, F. Baillifard, J. Demierre, D. Carrea, and M.-H. Derron (2015) Velocity prediction on time-variant landslides using moving response functions: Application to la barmasse rockslide (valais, switzerland). Engineering Geology for Society and Territory-Volume 2, pp. 323-327, Springer.

Alfonsi, P. (1997) Relation entre les paramètres hydrologiques et la vitesse dans les glissements de terrains. exemples de la clapière et de séchilienne (france). Revue française de géotechnique. 79: 3-12.

Belle, P., B. Aunay, S. Bernardie, G. Grandjean, B. Ladouche, R. Mazué, and J.-L. Join (2014) The application of an innovative inverse model for understanding and predicting landslide movements (salazie cirque landslides, reunion island). Landslides. 11(3): 343-355.

Bernardie, S., N. Desramaut, J.-P. Malet, M. Gourlay, and G. Grandjean (2014) Prediction of changes in landslide rates induced by rainfall. Landslides. pp. 1-14.

Cappa, F., Y. Guglielmi, S. Viseur, and S. Garambois (2014) Deep fluids can facilitate rupture of slow-moving giant landslides as a result of stress transfer and frictional weakening. Geophysical Research Letters. 41(1): 61-66.

Duranthon, J. P., J., L. Effendiantz, M. Memier, and I. Previtali (2003) Apport des méthodes topographiques et topométriques au suivi du versant rocheux instable des ruines de séchilienne. $X Y Z$. 94 : 31-38.

Durville, J., J. Kasperki, and J. Duranthon (2009) The séchilienne landslide: monitoring and kinematics, Proceedings of First Italian Workshop on Landslides. vol. 1, pp. 174-180.

Le Roux, O., D. Jongmans, J. Kasperski, S. Schwartz, P. Potherat, V. Lebrouc, R. Lagabrielle, and O. Meric (2011) Deep geophysical investigation of the large séchilienne landslide (western alps, france) and calibration with geological data. Engineering Geology. 120(1): 18-31.

Rochet, L., A. Giraud, P. Antoine, and H. Evrard (1994) La déformation du versant sud du mont-sec dans le secteur des ruines de séchilienne (isère). Bulletin of the International Association of Engineering Geology. 50(1) : 75-87.
Vallet, A., C. Bertrand, J. Mudry, T. Bogaard, O. Fabbri, C. Baudement, and B. Régent (2015b) Contribution of time-related environmental tracing combined with tracer tests for characterization of a groundwater conceptual model: a case study at the Séchilienne landslide, western alps (france). Hydrogeology journal. 23(8): 1761-1779.

Vallet, A., C. Bertrand, O. Fabbri, and J. Mudry (2015a) An efficient workflow to accurately compute groundwater recharge for the study of rainfall-triggered deep-seated landslides, application to the séchilienne unstable slope (western alps). Hydrology and Earth System Sciences. 19(1): 427-449.

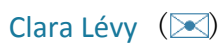

BRGM, Orléans 45060, France

E-mail: c.levy@brgm.fr

Scarlett Gendrey

BRGM, Orléans 45060, France

E-mail: s.gendrey@brgm.fr

Séverine Bernardie

BRGM, Orléans 45060, France

E-mail: s.bernardie@brgm.fr

Marie-Aurélie Chanut

Cerema, Bron 69500, France

E-mail: marie-aurelie.chanut@cerema.fr

Aurélien Vallet

BRGM, Orléans 45060, France

E-mail: a.vallet@brgm.fr

Laurent Dubois

Cerema, Bron 69500, France

E-mail: laurent.dubois@cerema.fr

Jean-Paul Duranthon

Cerema, Bron 69500, France

E-mail: jean-paul.duranthon@developpementdurable.gouv.fr 